\title{
APLIKASI OLAH DATA DAFTAR HADIR PADA PT. SEKINA AGUNG
}

\author{
Heribertus Tange ${ }^{1}$, Aswin Fitriansyah ${ }^{2}$, Bondan Dwi Hatmoko ${ }^{3}$ \\ Program Studi Informatika, Fakultas Teknik dan Ilmu Komputer, Universitas Indraprasta PGRI \\ Jalan Raya Tengah No 80, Kelurahan Gedong, Pasar Rebo, Jakarta Timur \\ bertustange@gmail.com ${ }^{1}$, aswin.fitriansyah@gmail.com ${ }^{2}$, royfoi@yahoo.co.id ${ }^{3}$
}

\begin{abstract}
Abstrak
Penelitian ini dilakukan dengan menggunakan metode grounded research yaitu sebuah metode yang dilakukan berdasarkan fakta yang sebenarnya dan menggunakan analisa perbandingan dengan tujuan mengadakan generalisasi empiris, menetapkan konsep, membuktikan teori, mengembangkan teori, pengumpulan data dan analisa data dalam waktu yang bersamaan. Tujuan penelitian adalah untuk mengindetifikasi membuat database sebagai tempat penampungan data daftar hadir pegawai agar tidak mudah hilang. Dari hasil pengujian yang telah dilakukan, peneliti menyimpulkan bahwa sistem aplikasi pengolahan data daftar hadir dapat membantu produktivitas dalam melakukan kegiatan pengolahan data pegawai. Dimana dalam membangun sistem ini digunakan alat bantu perancangan sistem yaitu Diagram Alir Data (DAD) Konteks, Nol dan Rinci serta dengan menggunakan bahasa pemrograman JAVA dengan Neatbeans IDE, dan database MYSQL menggunakan XAMPP.
\end{abstract}

Kata Kunci: Aplikasi olah data daftar hadir, Java, Netbeans, MySQL.

\begin{abstract}
This research is done using the grounded research method, which is a method done based on actual facts and using comparative analysis with the aim of holding empirical generalizations, establishing concepts, proving Theories, developing theories, data collection and data analysis at the same time. The purpose of the research is to identify creating a database as the Shelter data list present employees so as not easily lost. From the results of the tests that have been conducted, researchers concluded that the application System data processing list of present can help productivity in the processing activities of employee data. Where in building this system used system design tools namely Data flow Diagram (DAD) context, zero and detailed as well as using the JAVA programming language with the Neatbeans IDE, and the MYSQL database using XAMPP.
\end{abstract}

Keywords: Application data processing, present list, Java, Netbeans, MySQL.

\section{PENDAHULUAN}

Perkembangan teknologi sistem tidak lepas dari pesatnya perkembangan teknologi komputer, karena komputer merupakan media yang dapat memberikan memudahkan bagi manusia dalam menyelesaikan suatu pekerjaan. Sistem adalah hasil pengolahan data dari satu atau berbagai sumber yang kemudian dioleh sehingga memberikan nilai, arti dan manfaat (I Putu Agus Eka Pratama, 2014). Informasi adalah data yang diolah menjadi bentuk yang lebih berguna dan lebih berarti bagi penggunanya (Jogiyanto, 2014). PT. Sekina Agung merupakan salah satu perusahaan yang telah memakai sistem berupa pemakaian perangkat komputer dalam menjalankan aktivitas. Secara menyeluruh hanya memanfaatkan untuk hal-hal kecil saja, seperti dalam pembuatan suratsurat dan laporan-laporan serta dalam pengolahan data yang masih menggunakan Microsoft Word dan Microsoft Excel sehingga data-datanya masih belum tersusun secara rapi dan dapat menyebabkan terlambatnya pembuatan laporan karena sulitnya mendapatkan sistem dalam waktu yang cepat. Kendala yang ada pada pihak PT. Sekina Agung masih menggunakan penginputan data daftar hadir secara manual dan belum tersimpan secara terpadu dalam database. Data daftar hadir yang dihasilkan tidak dapat didistribusikan dengan cepat terutama kepada Pegawai. Solusi dari permasalahan di atas maka penyajian sistem sangat menunjang untuk mengurangi permasalahan tersebut, oleh karena itu peneliti tertarik untuk membangun suatu sistem "Sistem Aplikasi 
Pengolahan Data Daftar Hadir Menggunakan Java Netbeans Pada PT. Sekina Agung Kedoya Utara Jakarta Barat". Berdasarkan pembatasan permasalahan diatas tujuan dari penelitian ini adalah untuk membuat model rancangan sistem informasi penyimpanan dan pengolahan data absensi pegawai pada PT. Sekina Agung yang dapat membantu membantu produktivitas dalam melakukan kegiatan pengolahan data pegawai.

\section{PENELITIAN RELEVAN}

Dalam rangka mendapat hasil penelitian yang baik, selain melakukan penelitian langsung peneliti juga melakukan kajian perpustakaan dari hasil penelitian yang telah dilakukan. Berikut ini hasil penelitian yang menjadi acuan: "Perancangan Sistem Informasi Absensi Pada Unit Pelaksana Teknis Badan Kependudukan Dan Keluarga Berencana Daerah (UPTBKKBD) Kecamatan Sukaraja Sukabumi disusun oleh Nikye Nur Arafah Program Studi Informatika Fakultas Teknik Matematika dan Ilmu Pengetahuan Alam Universitas Indraprasta Persatuan Guru Republik Indonesia tahun 2016, di Jakarta. Tujuan penelitian diantaranya untuk membangun suatu sistem pengolahan data absensi pegawai. Kesimpulan yang diperoleh adalah Perubahan sistem absensi manual menjadi suatu sistem yang terkomputerisasi dilakukan agar tingkat kesalahan dalam melakukan absensi dapat diminimalisir dan dapat memberikan pelayanan yang baik serta hasil keluaran atau laporan yang dibutuhkan sesuai dengan yang diharapkan.

\section{METODE PENELITIAN}

Metode penelitian yang digunakan oleh peneliti adalah metode grounded (grounded research) yaitu suatu metode penelitian berdasarkan pada fakta dan menggunakan analisis perbandingan dengan tujuan mengadakan generalisasi empiris, menetapkan konsep, membuktikan teori, mengembangkan teori, pengumpulan dan analisis data dalam waktu yang bersamaan (Barnabas, 2012). Metode pengumpulan data yang digunakan peneliti untuk mendapatkan data dan informasi yang mendukung hasil dari penelitian ini antara lain: Studi Kepustakaan dan Studi Lapangan. Studi kepustakaan digunakan untuk pengumpulan data dan informasi dari kutipan-kutipan buku, peraturan perundang-undangan, artikel-artikel, hasil laporan, serta bahan lainnya yang berkaitan dengan penelitian ini. Dari bahan-bahan tersebut diambil teori-teori yang dijadikan landasan untuk menganalisa masalah yang ditemukan dalam penelitian dan digunakan untuk menyelesaikan masalah tersebut. Studi lapangan dilakukan dengan melihat langsung penerapan sistem daftar hadir yang ada di PT. Sekina Agung.

Dalam studi lapangan ini di pergunakan untuk teknik pengumpulan data antara lain dengan cara: Observasi dan Wawancara. Observasi adalah suatu cara pengumpulan data dengan mengadakan pengamatan langsung terhadap suatu objek dalam suatu periode tertentu yang diamati. Tujuan observasi yaitu untuk mengetahui secara langsung sistem daftar hadir pegawai di PT.Sekina Agung. Hasil observasi digunakan peneliti untuk mendapatkan data yang akurat dan relevan sesuai dengan tujuan penelitian. Wawancara adalah salah satu teknik pengumpulan data yang dilakukan dengan cara tanya jawab antara interviewer (penanya) dengan responden (penjawab). Dalam wawancara pada bulan September peneliti sebagai penanya dibantu oleh Ibu Linda sebagai penjawab selaku staff kepegawaian. Dalam wawancara ini peneliti bertanya mengenai program yang sudah ada, sejarah, dan data-data lain untuk melengkapi penelitian dan pembuatan program.

\section{HASIL DAN PEMBAHASAN}

Adapun aturan yang diusulkan pada sistem informasi pengolahan data daftar hadir pegawai sebagai berikut:

1. Penginputan Data Pegawai

Prosedur ini dilakukan oleh staff kepegawaian sebagai unit operator yang bertugas untuk mengelola sistem daftar hadir pegawai, dimana staff ini menginput data pegawai di ruang lingkup PT. Sekina Agung.

2. Penginputan Data Daftar Hadir Reguler

Prosedur ini dilakukan oleh staff operator dimana staff unit operator menginput data daftar hadir regular setiap harinya. 
3. Penginputan Data Daftar Hadir

Prosedur ini dilakukan oleh seluruh pegawai PT. Sekina Agung dimana seluruh pegawai melakukan pengisian daftar hadir jam masuk serta jam pulang ke dalam mesin clock dengan cara memasukan kertas daftar hadir dimana masing-masing pegawai mempunyai kertas daftar hadir masing-masing.

4. Penginputan Data User

Prosedur ini dilakukan oleh admin yang bertugas sebagai penanggung jawab atas sistem yang berjalan di PT. Sekina Agung.

5. Pembuatan Laporan

Staff unit operator diharuskan membuat laporan data kehadiran pegawai dari data daftar hadir seluruh pegawai setiap bulannya untuk diserahkan kepada atasannya.(Jogiyanto, 2014)

\section{Diagram Alir Data (DAD) Sistem Yang Diusulkan (Diagram Konteks, Nol Dan Rinci)}

Diagram Konteks:

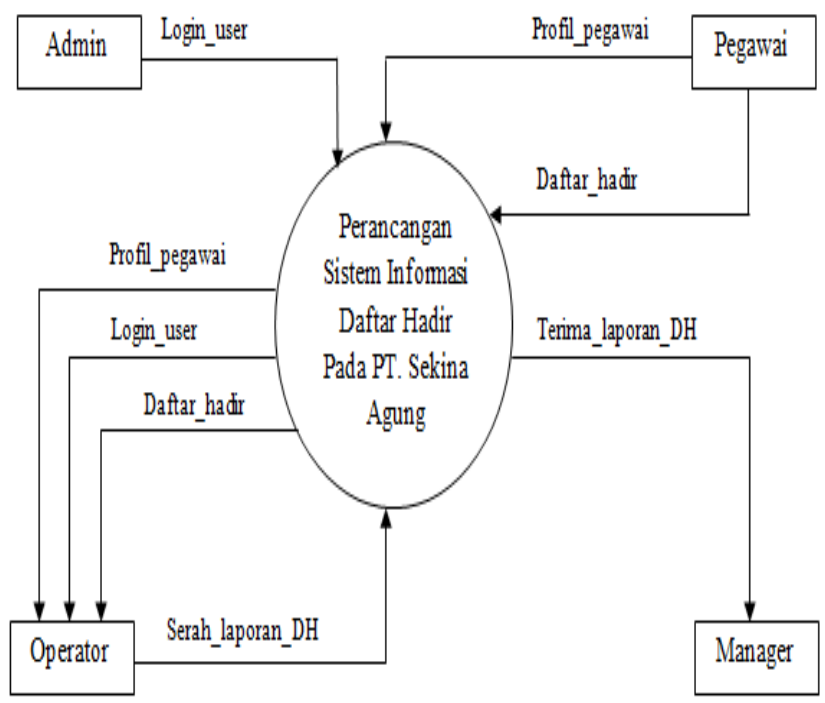

Gambar 1. Diagram konteks

Diagram Nol:

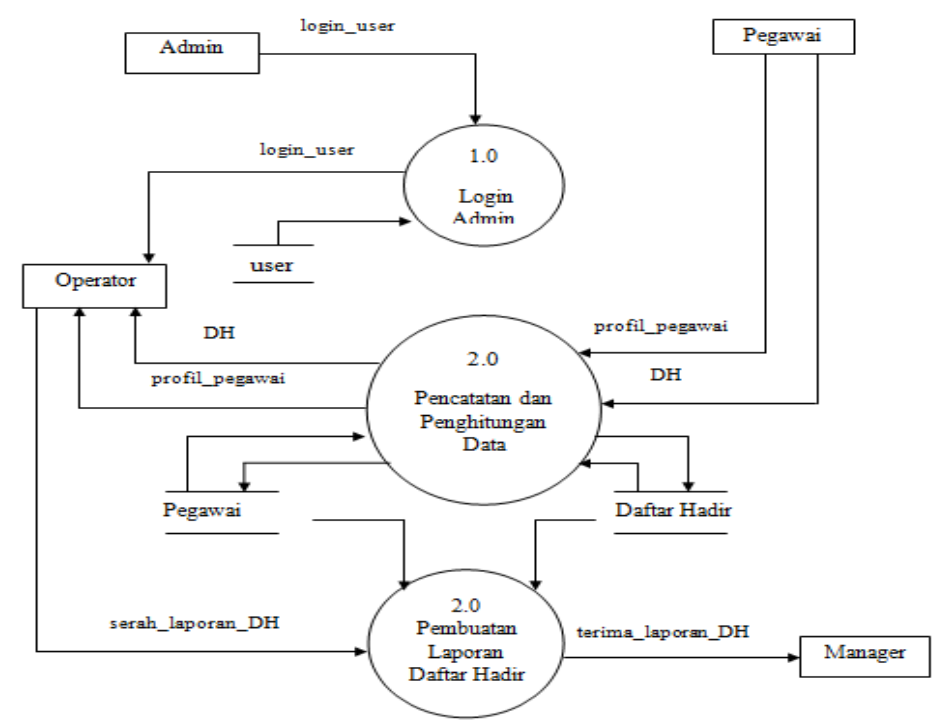

Gambar 2. Diagram nol 


\section{ERD (Entity Relationship Diagram)}

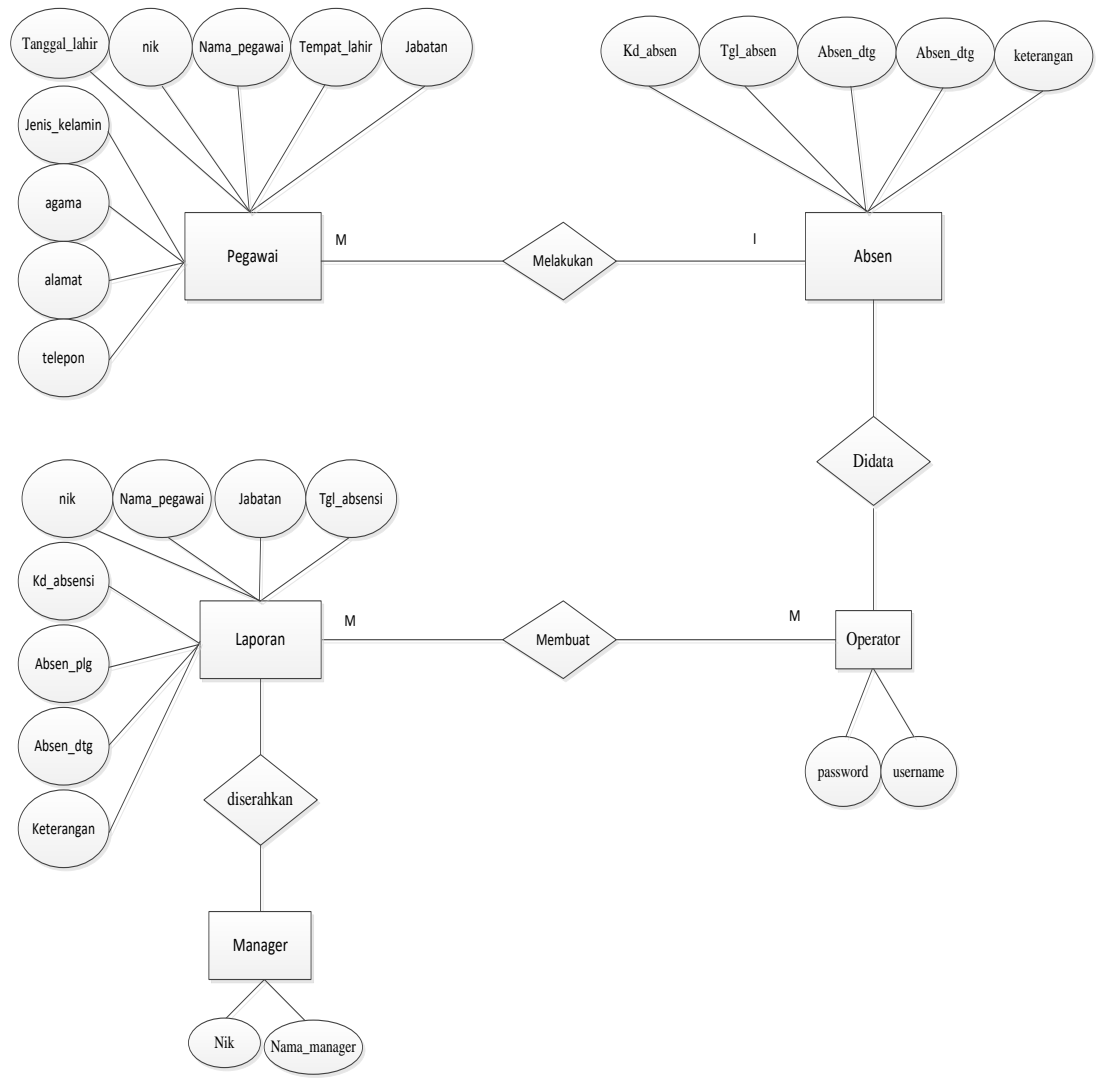

Gambar 3. Entity Relationship Diagram (ERD)

\section{Tampilan Layar, Tampilan Format Masukan Dan Tampilan Keluaran} Tampilan Menu Utama

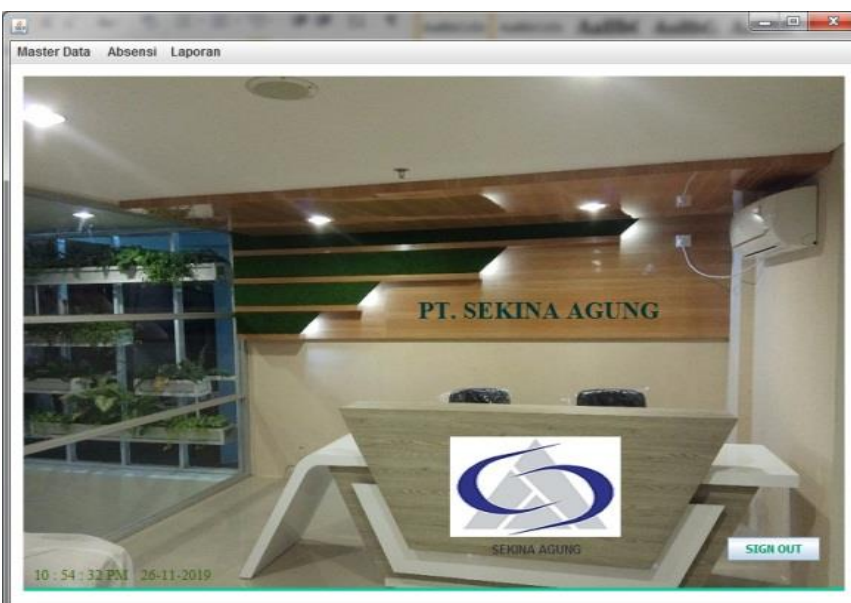

Gambar 4. Tampilan menu utama

Tampilan menu utama ini terdapat beberapa buttom menu yang akan menampilkan from-from masukan dan keluaran. Menu PT. Sekina Agung akan menampilkan gambar background yang berisikan inputan dan laporan-laporan. 


\section{Tampilan Data Pegawai}

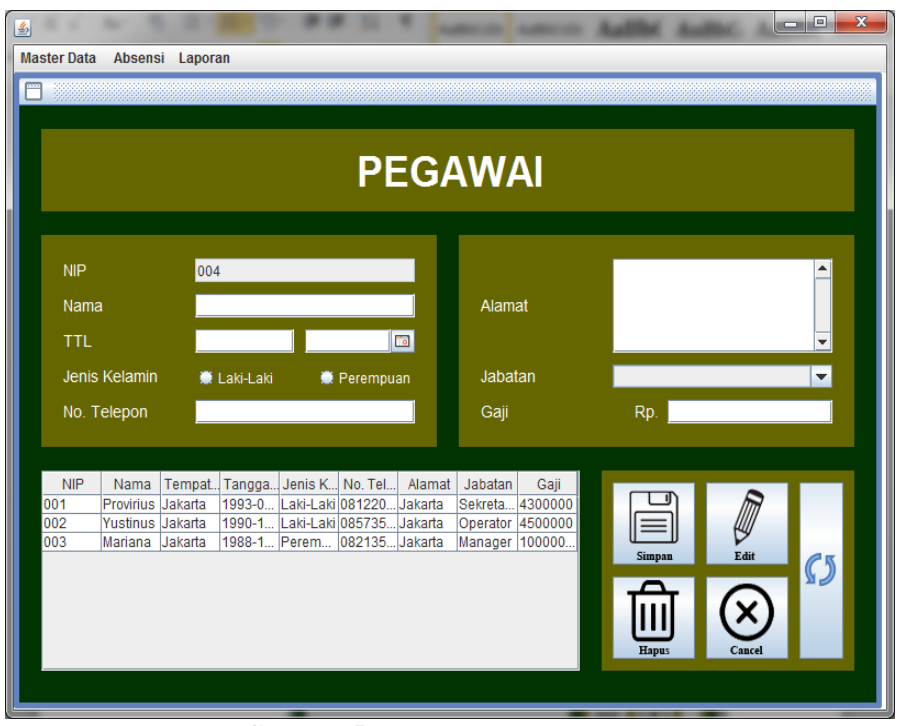

Gambar 5. Tampilan Data Pegawai

Pada tampilan diatas merupakan tampilan data pegawai. Form ini memiliki beberapa tombol yang terdiri dari tombol Simpan untuk menyimpan data pegawai, tombol Edit untuk mengedit inputan data, tombol Hapus untuk menghapus data inputan data, tombol Cancel untuk kembali ke menu utama, tombol Refresh untuk mengrefresh data.

\section{Tampilan Data Jam Masuk}

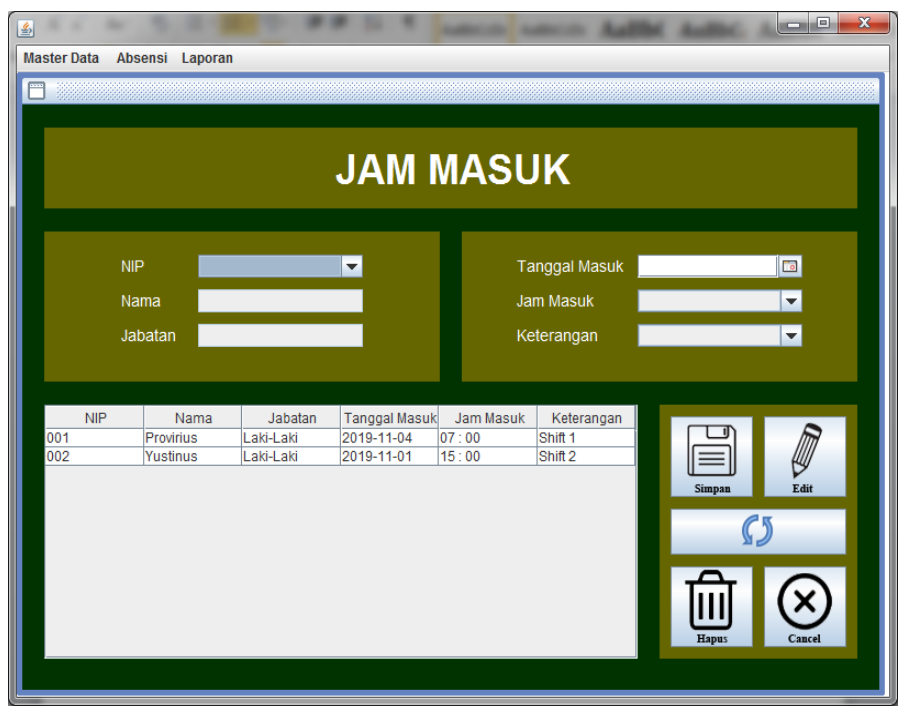

Gambar 6. Tampilan Data Jam Masuk

Pada tampilan diatas merupakan tampilan data jam masuk. Form ini memiliki beberapa tombol yang terdiri dari tombol Simpan untuk menyimpan data pegawai, tombol Edit untuk mengedit inputan data, tombol Hapus untuk menghapus data inputan data, tombol Cancel untuk kembali ke menu utama, tombol Refresh untuk mengrefresh data. 


\section{Tampilan Data Jam Keluar}

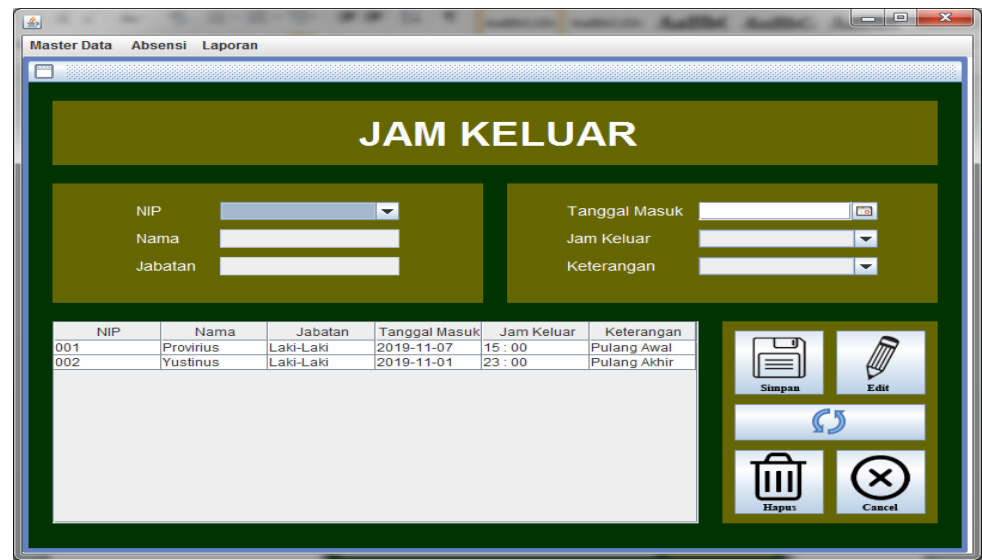

Gambar 7. Tampilan Data Jam Keluar

Pada tampilan diatas merupakan tampilan data jam keluar. Form ini memiliki beberapa tombol yang terdiri dari tombol Simpan untuk menyimpan data pegawai, tombol Edit untuk mengedit inputan data, tombol Hapus untuk menghapus data inputan data, tombol Cancel untuk kembali ke menu utama, tombol Refresh untuk mengrefresh data.

\section{Tampilan Laporan Data Pegawai}

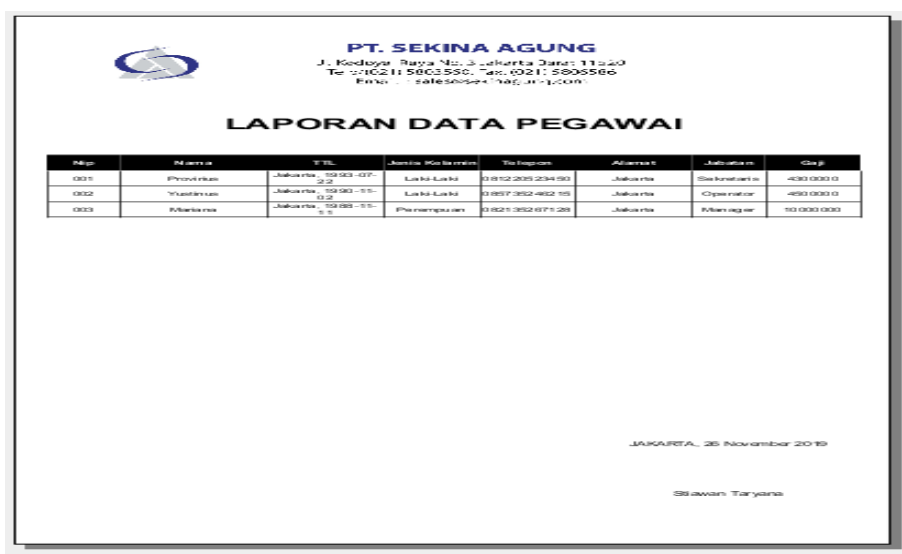

Gambar 8. Tampilan Lapora Data Pegawai

Pada tampilan file laporan ini berisi tentang laporan data pegawai yang didapat dari admin sebagai bukti laporan data pegawai yang telah dilakukan.

\section{Tampilan Laporan Data Jam Masuk}

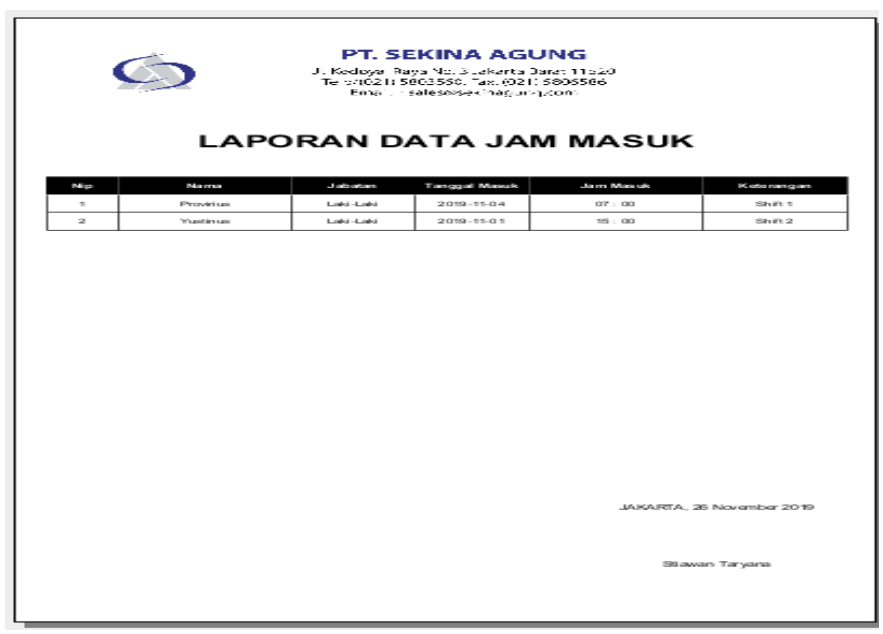

Gambar 9. Tampilan Laporan Data Jam Masuk 
Pada tampilan file laporan ini berisi tentang laporan data jam masuk yang didapat dari admin sebagai bukti laporan data jam masuk yang telah dilakukan.

\section{Tampilan Laporan Data Jam Keluar}

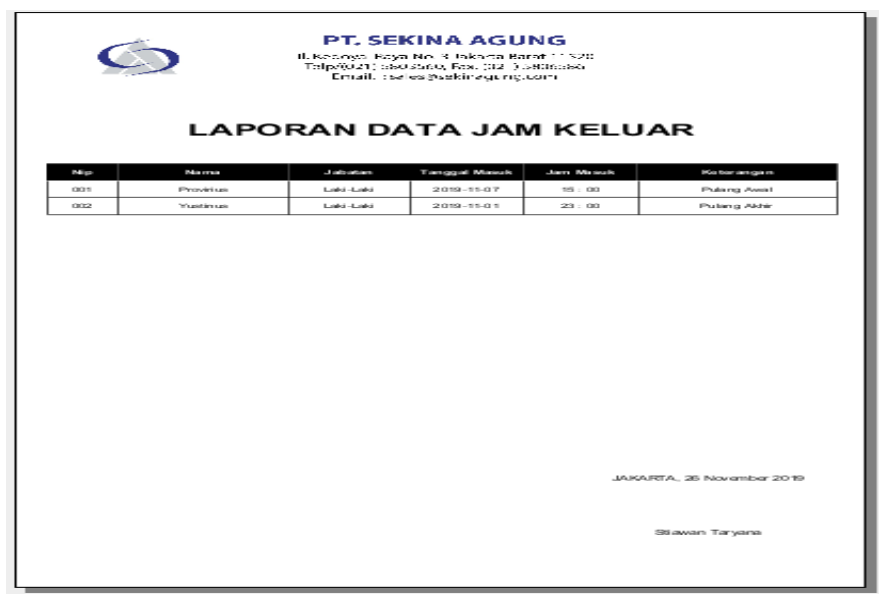

Gambar 10. Tampilan Laporan Data Jam Keluar

Pada tampilan file laporan ini berisi tentang laporan data jam keluar yang didapat dari admin sebagai bukti laporan data jam keluar yang telah dilakukan.

\section{SIMPULAN}

Setelah aplikasi ini dibuat, pada bagian pendataan dapat memberikan informasi dengan cepat, tepat dan tidak memerlukan banyak waktu dalam memperoleh informasi. Selain itu penyajian informasi tidak dapat dan terdapat kesalahan-kesalahan pada pendataan, tetapi dengan adanya aplikasi ini, penyajian informasi akan tepat dan kesalahan-kesalahan dapat diatasi dengan baik agar tidak terjadi hambatan dalam penyajian informasi.

\section{DAFTAR PUSTAKA}

Barnabas, B. (2012). Metode Penelitian Grounded Research.

https://www.academia.edu/8363807/Grounded_Research_Grounded_Theory_Metode_Penelitian_Grounded_oleh _Baren_Barnabas?auto=download Fathansyah. (2012). Basis Data (informatik).

I Putu Agus Eka Pratama. (2014). Sistem Informasi Dan Implementasinya. Indrajani. (2015). Definisi Basis Data. Elex Media Komputindo.

Jogiyanto. (2014). Analisia Dan Kamus Data (A. Offset (ed.)). 